\title{
The Contribution of Functional Load on Children's Vocalic Development
}

\author{
Margaret Cychosz and Susan E. Kalt \\ University of California, Berkeley \& Roxbury Community College
}

\section{Introduction}

Children's phonology is replete with regular, predictable phenomena that nevertheless differ from adults (Pater \& Barlow, 2004; Inkelas \& Rose, 2007). Discrepancies between adult and late-childhood speech cannot be solely attributed to environmental input, so immature motor development is often cited. Normally-developing children quickly acquire the motor skills and segment planning necessary to avoid these "errors", a tendency illustrated by child phonologists' focus on the early years of $1 ; 6-4 ; 0$.

But phonological development continues well into late-childhood. For example, as a child's vocabulary grows, the mental lexicon is in a constant state of restructuring. This has ramifications for the effects of word frequency and phonological neighborhood density on children's consonant production (Storkel \& Morrisette, 2002). In addition to this, the duration and acoustic variability of children's speech segments also decreases with age in English (Lee et al., 1999) and French (Ménard et al., 2007). These patterns are generally attributed to physiological development, either children's anatomical difference from adults (Denny \& McGowan, 2012) or their underdeveloped motor routines (McAllister Byun, 2011).

Here we present contradictory data from Chuquisaca Quechua (CQ) that show children producing shorter vowel durations than adults and propose that language-internal factors may mitigate physiological constraints. If anatomy were solely responsible for the durational differences between adult and child speakers, we would not see durational disparities between consonants and vowels. Instead, we attribute this unexpected pattern to the role of FUNCTIONAL LOAD (FL), or the contrastive work that a sound performs in a language. As an agglutinating language, CQ's many suffixes may carry more weight relative to roots in the child lexicon. How suffixes are organized within the mental lexicon - in languages with morphological typologies ranging from analytic to polysynthetic - is far from clear. But in a language such as CQ, where words commonly contain four or five suffixes, morphology may play a role in phonological development.

Just like phonological neighborhood density and other psycholinguistic measures, FL will reorganize as the lexicon develops. Although interest in FL as an explanatory device for phoneme mergers and inventories has recently resurfaced (Hockett, 1955; Surendran \& Niyogi, 2006; Oh et al., 2013; Wedel et al., 2013), only a handful of studies have quantified it for children's phonological acquisition (Pye et al. 1987; Stokes \& Surendran, 2005; Van Severen et al., 2013; Cychosz, 2018). This is somewhat surprising since the role of other ambient language effects, especially frequency, upon phonological emergence and mastery is well-attested (see Edwards, Beckman, \& Munson, 2015 for overview). These studies assume that children accurately produce sounds that are highly frequent in the input because they can 1) practice the required motor routine and 2) abstract the sound away from its lexical context and access it more easily. These findings contrast starkly with universalist views of development (Jakobson, 1941/1968). So, much like frequency, FL contributes to the ongoing exploration of cross-linguistic similarities in phonological development.

\footnotetext{
* We extend our sincerest thanks to the families and schools of the Chuquisaca region as well as numerous collaborators in Bolivia and Peru who lent their time and energies for this data collection, including interviewers María Cristina Parackahua Arancibia, Martín Castillo Collado, and Pedro Plaza Martínez, illustrator Jaime Aráoz Chacón, and transcriptionists Alfredo Quiroz Villarroel and Janett Vengoa de Orós. For helpful discussion, we also thank Chris Hench, Sharon Inkelas, Nik Rolle, Susan Lin, Clifton Pye, and the audience at AMP 2017. Errors and omissions remain our own.
}

(C) 2018 Margaret Cychosz \& Susan Kalt

Proceedings of AMP 2017 
Children are cognizant of relevant contrasts in their language from infancy. By 5;0, they employ production strategies, such as a shortened segment duration, based on their own, unique phonological neighborhood densities (Charles-Luce \& Luce, 1990; Storkel \& Morrisette, 2002; Storkel \& Hoover, 2011). FL is an important metric to test in the context of speech development because a child's lexicon is not simply a miniature version of an adult's; for example, the child lexicon is less dense and items may be stored holistically without the same amount of phonetic detail as adult lexical representations (CharlesLuce \& Luce 1990; Storkel 2002). In CQ, there are additional differences. Quechuan languages are highly agglutinative and children are morphologically productive by 5;0 (Courtney \& Saville-Troike, 2002; Courtney 2015; Kalt, 2015). But while the morphological lexicon develops early on, a complete root word lexicon takes many years, growing until early adolescence as children learn more and more words. As a result, we can anticipate maximal distinctiveness between adult and child CQ lexica. This structural difference may cause children to make different generalizations over their lexicon about the relative importance of phonological contrasts. These differences could then manifest as different production strategies between adults and children.

\section{Chuquisaca Quechua}

2.1 Language CQ is a variety of South Bolivian Quechua, a Quechua II-C language spoken by over 1.6 million people in the vicinities surrounding Cochabamba, Bolivia and northwest Argentina (Torero, 1964; Simons, 2009). It is highly agglutinative with a series of nominal and verbal suffixes. CQ has a three vowel /a, i, u/ system, with corresponding mid-vowels [e, o] derived in uvular contexts (Gallagher, 2016). Table 1 lists the consonant inventory. Only allophones that are relevant for the current analysis are included.

\begin{tabular}{l|ccccccc} 
& LABIAL & DENTAL & POSTALVEOLAR & PALATAL & VELAR & UVULAR & GLOTTAL \\
\hline plosive & $\mathrm{p}$ & $\mathrm{t}$ & $\mathrm{t} f$ & & $\mathrm{k}$ & $\mathrm{q}$ & \\
aspirate & $\mathrm{p}^{\mathrm{h}}$ & $\mathrm{t}^{\mathrm{h}}$ & $\mathrm{t} \int^{\mathrm{h}}$ & & $\mathrm{k}^{\mathrm{h}}$ & $\mathrm{q}^{\mathrm{h}}$ & \\
ejective & $\mathrm{p}$ & $\mathrm{t}$ & $\mathrm{t} \mathrm{f}^{\prime}$ & & $\mathrm{k}$ & $\mathrm{q}$ & \\
fricative & & $\mathrm{s}$ & $\left(\int\right)$ & & & & $\mathrm{h}$ \\
nasal & $\mathrm{m}$ & $\mathrm{n}$ & & $\mathrm{n}$ & & & \\
tap & & $\mathrm{f}$ & & & & & \\
liquid & & 1 & & $\mathrm{j}$ & & & \\
glide & $\mathrm{w}$ & & & & &
\end{tabular}

Table 1: Consonant inventory of Chuquisaca Quechua

2.2 Segments analyzed In the corpus used for the analysis, mid-vowels were relatively lowfrequency and limited to only certain lexical items. As a result, only peripheral vowels /a, i, u/ were examined. Beckman \& Edwards (2008) report that Cantonese children $(2 ; 0-3 ; 0)$ were less accurate in the production of an allophonic palatalized velar stop than the velar stop phoneme. So it is possible that CQ vowel allophony plays a role in the relationship between segment duration and FL, but vowel allophony will not be addressed here.

To illustrate a potential relationship between FL and duration, and to control for the effect of speaking rate, the FL of a subset of CQ consonants was also measured: $/ \mathrm{m}, \mathrm{n}, \mathrm{s}, \mathrm{t} \int \mathcal{\sim} /$. Fricatives and nasals were chosen for practical reasons: nasal/fricative duration is more straightforward to measure than the duration of ejectives or voiceless stops. [ $\mathrm{f}]$ is derived of $\mathrm{CQ} / \mathrm{t} \mathrm{f} /$ in fast speech and so both are included.

\section{Research questions}

The two hypotheses are:

1) The functional load calculated over Chuquisaca Quechua suffixes will differ from the functional load of root words. 
CQ phonotactics differ slightly by morphological status. Roots are generally two syllables and follow a CV.CV pattern. However suffixes are often composed of one syllable, though there are exceptions (e.g. -manta ABLATIVE). In addition, the onsets of roots are singleton consonants or, less frequently, vowels. But suffixes may also begin with consonant clusters (e.g. $-r q a$ EXPERIENCED PAST) or contain consonants in coda position (e.g. - man DATIVE) which is less frequent in root words.

The consonants examined, nasals and fricatives, follow the expected developmental pattern - the children's consonants are longer in duration than the adults'. But children's vowels are shorter which warrants explanation. While a number of factors might explain this, we examine FL. Adult speakers calculate the FL of segments in their ambient language. In an effort to be efficient (Aylett \& Turk, 2004), speakers adapt their acoustics to reflect "important" (e.g. heavily contrastive) segments that are less predictable from context (Jurafsky et al., 2001). Wedel et al. (2013) predict that phones that distinguish minimal pairs "will be produced, on average, with more exaggerated phonetic cues" (184). These studies suggest that when a segment is less predictable from syntactic, semantic or prosodic context, as phones in contrastive environments are, it will be acoustically enhanced, often with a longer duration. However, no study that we are aware of has attempted to correlate the variability in children's production with FL.

2) FL will correlate with the observed segment duration patterns across adult and child speakers.

Unlike previous reports, we find that CQ children's vowels are shorter than those of adults. If FL can explain this developmental pattern, we would expect to see that the FL of vowels is lower in children than in adults. However, since children produce longer consonants than adults, we should correspondingly see that the FL of consonants is higher for children than adults.

\section{Methods}

4.1 Participants Child speakers were recorded at school in two agro-pastoralist communities ${ }^{1}$ located approximately two hours' hike from the small town of Tarabuco in the Chuquisaca department of Bolivia. Each community had less than 120 households and CQ was the dominant language. The recordings used for this study are part of a larger comparative corpus of interviews conducted in rural Cuzco, Peru and Chuquisaca, Bolivia which the second author collected collaborating with field partners in both countries Bolivia (Kalt, 2009; Kalt, to appear).

After excluding two child participants due to highly breathy speech, the dataset consisted of $N=26$ children ( 14 female, 12 male) and $N=2$ adults ( 1 female, 1 male) for comparison. The children were divided into an older (age 8;0-10;0, $N=19$ ) and younger cohort (age 5;0-7;0, $N=7$ ). Our team's access to these communities was limited by their remoteness, which resulted in the unbalanced age groups. The children may be classified as sequential Quechua-Spanish bilinguals; though at this young age they are dominant in CQ. Children in the communities learn and speak CQ in the home and begin to learn Spanish upon entering kindergarten around 5;0. The adult female (age 34) reported receiving some primary school education in Spanish and stated that she did not speak Spanish. The adult male (age 78) reported one month of primary education and also stated that he did not speak Spanish.

4.2 Stimuli and recordings Data consisted of audio and video recordings of the child participants completing a picture selection and description task with culturally-appropriate images and contexts based on Kalt (2002) (appendix 1). The adult speakers narrated the Duck Story, an open-ended comic strip which our team also created (appendix 2). All participants responded to questions posed by a native or heritage speaker interlocutor. The audio data was recorded with an Audio Technica AT899 lavalier microphone at a $20 \mathrm{kHz}$ sampling rate and the video data with a Canon Vixia HF-100 camcorder. The result is naturalistic speech with relative inter-speaker homogeneity, at least within the children and adults. Bolivian and Peruvian native Quechua speakers transcribed and morphologically segmented each interview in collaboration with the second author.

\footnotetext{
${ }^{1}$ Names rescinded for confidentiality.
} 
4.3 Phonetic analysis Each audio recording was first segmented into participant versus interviewer speech in ELAN (Sloetjes \& Wittenburg, 2008). The recording was then aligned with the morphological transcriptions in Praat (Boersma \& Weenink, 2016) and the first author wrote a Python script ad hoc to parse the morphological transcriptions into phone-level transcriptions which she hand-aligned.

Acoustic measurements (duration, F1-F3, f0) for the segments of interest $/ \mathrm{s}, \mathrm{n}, \mathrm{m}, \int \sim \mathrm{t} / \mathrm{a}$ and all peripheral vowels were automatically extracted using a script running IFC Formant (Watanabe 2001). Only duration is addressed here. This resulted in a total of $N=4709$ tokens of child speech and $N=838$ adult. Token counts per segment are listed in table 2 .

\begin{tabular}{c|cccccccc} 
& $\mathrm{n}$ & $\mathrm{m}$ & $\mathrm{s}$ & $\mathrm{t} \sim \int$ & $\mathrm{a}$ & $\mathrm{i}$ & $\mathrm{u}$ & TOTAL \\
\hline $5 ; 0-7 ; 0$ & 219 & 109 & 49 & $50 \sim 59$ & 454 & 120 & 152 & 1212 \\
& $(31)$ & $(16)$ & $(7)$ & $(7 \sim 8)$ & $(65)$ & $(17)$ & $(22)$ & \\
$8 ; 0-10 ; 0$ & 520 & 286 & 113 & $205 \sim 163$ & 1211 & 402 & 597 & 3497 \\
& $(23)$ & $(14)$ & $(5)$ & $(10 \sim 9)$ & $(64)$ & $(21)$ & $(31)$ & \\
ADULTS & 166 & 59 & 59 & $56 \sim 25$ & 265 & 117 & 91 & 838 \\
& $(83)$ & $(27)$ & $(30)$ & $(28 \sim 13)$ & $(131)$ & $(58)$ & $(45)$ & \\
TotAL & 905 & 454 & 221 & 558 & 1930 & 639 & 840 & 5547
\end{tabular}

Table 2: Token counts by segment across all speakers. Average number of tokens per speaker in parentheses.

4.4 Calculations In its simplest form, FL quantifies the number of minimal pairs that a single sound distinguishes in a language. The FL of a given phoneme is formally defined as the system entropy loss resultant from that phoneme's convergence with another phoneme or loss from the language:

$$
F L_{U}(a)=\frac{C L_{U}-C\left(L_{U}^{-a}\right)}{C L_{U}}
$$

where $a$ is the linguistic unit, $C$ is entropy, and $L_{U}$ is the linguistic system. In general, the phoneme convergence or loss results in a tradeoff of decreased entropy but heightened homophony. Here we calculate system entropy at the word level but note that phoneme-level entropy is another method for FL calculation (Surendran \& Niyogi, 2006).

FL was measured over a 25,457 word lexicon of South Bolivian Quechua, of which CQ is a variety, that contained separate entries for roots and suffixes (Heggarty, 2006). The roots we analyzed did not include any morphological affixes, including inflectional ones. After removing all homonyms $(14.42 \%$ of lexicon), calculations were made separately over suffixes and roots for adults and children. Since no child lexicon of any Quechuan language is available, a pseudo-child CQ lexicon was created via a bootstrapping procedure: FL was calculated over 5,000 root words randomly sampled from the corpus. This was done 100 times and averaged. While we acknowledge that a child's lexicon is not simply a miniaturized version of an adult's - the content differs substantially as well - in the absence of any child lexica or naturalistic databases of Quechuan languages, this is the best method at this time. Each subsample consisted of 5,000 words because previous work estimates this as the size of a 5;0 child's vocabulary (Anglin et al., 1993). FL was calculated over the entire suffix inventory $(N=213)$ for both adults and children because, once again, work on morphological development in Peruvian Quechua varieties (Courtney \& Saville-Troike, 2002; Courtney 2015; Kalt 2015) has demonstrated that children are morphologically productive by $5 ; 0$. Consequently, here we assume that children have acquired the full suffix lexicon. If the FL differs between adults and children, it could be an artifact of a greatly reduced root inventory in children.

To corroborate the hypothesized relationship between vowel duration and functional load, child FL was also calculated for Hexagonal French over the same consonants subset /m, n, s, t $\int \mathcal{\sim} /$ and all French oral and nasal vowels (/a, a, œ, ø, e, i, y, $\varepsilon, o, ~ o, ~ u, ~ ə, ~ \tilde{a}, \tilde{\varepsilon}, \tilde{e}, \tilde{\jmath} /)$. French was chosen because it has a similar nasal/fricative inventory as CQ, which allows for a more direct comparison. Even though the size of the vowel inventory differs between French and CQ, we calculate over the entire inventory in both cases so 
there is no reason a priori why FL should differ between the systems. For the calculation, the same pseudolexicon bootstrapping procedure as above was employed but over the French lexicon LEXIQUE (New et al., 2001) ( $N=71,327$ after homonym removal).

\section{$5 \quad$ Results}

5.1 Duration Statistical analyses were carried out in R (R Core Team, 2015) using the lme4 (Bates et al., 2015) and lmerTest (Kuznetsova et al., 2013) packages. Outliers $>300 \mathrm{~ms}$ were removed (vowel: $N=13$, consonant: $N=20$ ). Figure 1 maps the duration of peripheral vowels and consonants across adult and child speakers. Children follow the expected developmental pattern of producing longer duration consonants than adults $(5 ; 0-7 ; 0: 115.37 \mathrm{~ms} \pm 53.28,8 ; 0-10 ; 0: 103.98 \pm 53.46$, adults: $79.66 \pm 33.31$ across all consonants). This holds true for both child age groups. However for vowels, the 5;0-7;0 children and the $8 ; 0-10 ; 0$ children's productions are shorter than adults $(5 ; 0-7 ; 0: 91.41 \mathrm{~ms} \pm 41.93,8 ; 0-10 ; 0: 82.31 \pm 34.29$, adults: $101.87 \pm 45.50$ across all vowels). The $8 ; 0-10 ; 0$ age group produced shorter duration vowels than even the $5 ; 0-7 ; 0$ age group.

Two linear mixed effects models were fit to predict consonant or vowel duration with random intercepts for vowel/consonant. Results showed that age group was a significant parameter of each model, Specifically, the $5 ; 0-7 ; 0$ child group's consonant duration was longer than adult $(\beta=38.791, t=12.301$, $p<.001)$ as was the $8 ; 0-10 ; 0$ group $(\beta=19.571, t=7.139, p<.001)$. (Beta values represent the dependent variable value so on average, the $5 ; 0-7 ; 0$ group produced consonants that were approximately $39 \mathrm{~ms}$ longer than the adults). But child vowel duration was shorter for both groups than for adults $(5 ; 0-7 ; 0: \beta=-10.946$, $t=-4.905, p<.001,8 ; 0-10 ; 0: \beta=-19.508, t=-10.181, p<.001)$.

Note that neither vowel nor consonant length is contrastive in CQ - long vowels occur only in derived environments. In addition, the disparity between phone type in the children's speech - longer consonants but shorter vowels - implicitly controls for speech rate, suggesting that neither rate of speech nor underdeveloped motor skills can be the sole explanation for this pattern.
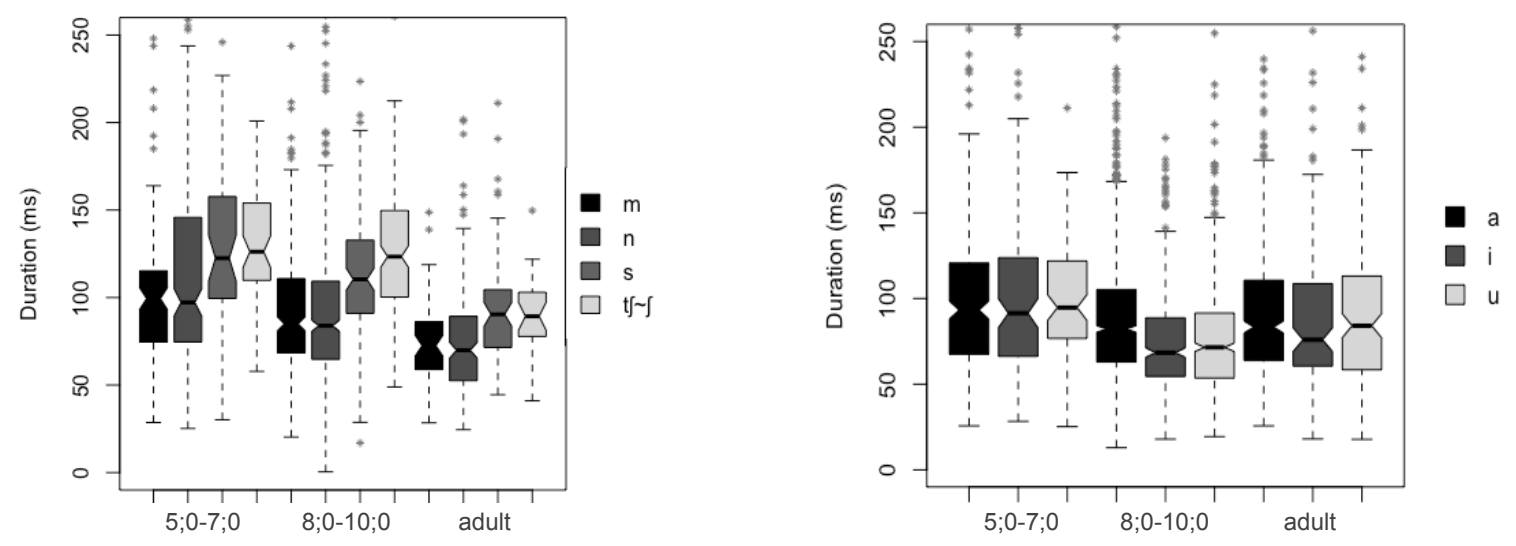

Figure 1: Consonant (L) and vowel (R) duration by age.

The median is represented with the horizontal belt and whiskers represent $1.5 \mathrm{x}$ the interquartile range.

5.2 Functional load Results from the FL calculations are given in tables 3 for CQ and 4 for French. For the adult CQ lexicon, with all root words and suffixes, the FL of vowels is much higher than for the consonant subset. However, in the pseudo-child lexicon, the disparity between vowel and consonant FL is much less. The FL of suffixes holds the answer: overall, the FL of vowels is almost equal to that of consonants in CQ suffixes.

In the pseudo-French child lexicon, vowels have a higher FL than the consonant subset. This is just like the situation for CQ adults. In both cases, vowels carry a larger functional load than the consonant 
subset in the mental lexicon and, correspondingly, vowels are longer in duration. Note that FL is only a relative measurement - it is not appropriate to compare raw values between CQ and French, for example, given the different lexica that provided the measurement.

\begin{tabular}{|c|c|c|c|}
\hline & $\begin{array}{c}\text { SUFFIXES + ALL } \\
\text { ROOTS } \\
\text { [ADULT LEXICON] }\end{array}$ & $\begin{array}{l}\text { SUFFIXES }+5,000 \\
\text { ROOTS [PSEUDO- } \\
\text { CHILD LEXICON] }\end{array}$ & SUFFIXES ONLY \\
\hline $\begin{array}{l}\text { VOWELS } \\
/ \mathrm{m}, \mathrm{n}, \mathrm{s}, \mathrm{t} \int \sim /\end{array}$ & $\begin{array}{l}0.215 \\
0.086\end{array}$ & $\begin{array}{l}0.098 \\
0.035\end{array}$ & $\begin{array}{l}0.175 \\
0.137\end{array}$ \\
\hline
\end{tabular}

Table 3: Functional load in CQ suffixes and roots

\begin{tabular}{l|c} 
& $\begin{array}{c}\text { SuFfiXes }+5,000 \\
\text { RoOTS [PSEUDO- } \\
\text { CHILD LEXICON] }\end{array}$ \\
\hline VOWELS & 0.218 \\
\hline$/ \mathrm{m}, \mathrm{n}, \mathrm{s}, \mathrm{t} f, \int /$ & 0.006
\end{tabular}

Table 4: Functional load in a French child's lexicon

\section{Conclusion and discussion}

Our results affirm the first hypothesis that the FL of CQ vowels would differ across suffixes and roots. Specifically, vowels and consonants have almost identical contrastive responsibilities in CQ suffixes. But in the full adult lexicon, vowels have a higher FL than the consonant subset $(0.215$ versus 0.086$)$. The difference between FL in the adult and pseudo-child lexica suggests that the calculations that children make regarding FL, as addressed here, or other metrics such as word frequency and phonological neighborhood density, may differ between adults and children as well as cross-linguistically. We already know that the lexicon can be responsible for the different phonological generalizations that children make. For example, the Holistic Lexical Organization Hypothesis (Charles-Luce \& Luce 1990) argued that children, with their sparse phonological neighborhoods, initially store and access words holistically without the need to encode phonetic detail. Edwards, Beckman, \& Munson (2004) demonstrated that children 3;2-8;10 were more accurate at producing high frequency two-phoneme sequences than low frequency sequences, though this effect was heightened for children with smaller vocabularies. And in a study of children 2;11-6;0, Storkel \& Hoover (2011) found that an increased phonotactic probability only boosted acquisition rates of nonce words in children with large expressive vocabularies. Children with lower vocabulary scores did not show any effect.

Here we have added to the growing body of work that documents the structure of the developing lexicon. We also examined the interaction between the lexicon and production and we incorporated a new language into the theory that offers important typological diversity and insight. Assuming that the physiological development of the children in this study does not differ from previously-studied children, and acknowledging the possible task effect since the data are quasi-naturalistic, we can preliminarily propose a language-specific reason for the CQ children's shorter segment durations: the agglutinating structure of the language. This lends support to the primacy of the input in phonological development and how it may interact with known physiological universals.

We acknowledge that the child and adult speakers in this study may have different exposure to Spanish. For example, some of the older children had already been in school for several years, regularly speaking and listening to Spanish. Until we are able to collect data from adults who have been educated in a similar environment, this will remain a confounding factor. Still, the younger children in our study did not have significant experience with Spanish at school yet. In fact, their exposure likely resembled the adult participants: passive listening. And we emphasize that both groups of children produced shorter vowels than the adult speakers. 
CQ offers an important contribution to our understanding of lexical growth because its structure means that the child lexicon differs from the adult in a way that western European languages such as English or French may not. The differences between the adult and child lexicon, due in large part to the morphology, suggest that theories on lexicon development must incorporate typologically underrepresented languages.

The second hypothesis proposed that FL would correlate with the vowel and consonant duration patterns across adult and child speakers; specifically, children should have a higher FL for their vowels than consonants. Once again, this is due to the disproportionate representation of suffixes in the child lexicon, where vowels and consonants have a roughly equal contrastive load. Even after factoring out speaking rate and motor limitation - after all, the children still produced significantly longer consonants than the adults - the disparity in vowel duration between adults and children remained.

Our FL calculations for child and adult CQ speakers corroborated these results and confirmed findings from recent years concerning the role of predictability and phonetic reduction. From this we can propose that segments that do more work in a language, via distinguishing more minimal pairs for example, will have more salient acoustic characteristics. This is exactly the result that we saw in the analyses: adults, with a larger ratio of vowel to consonant FL, produced longer duration vowels. This theory of development predicts that as child speakers of CQ or other morphologically rich languages age into early adolescence, their vowel durations should actually become longer, reflecting the changing representation of suffixes and morphology in the lexicon. 


\section{Appendices}

7.1 Appendix 1
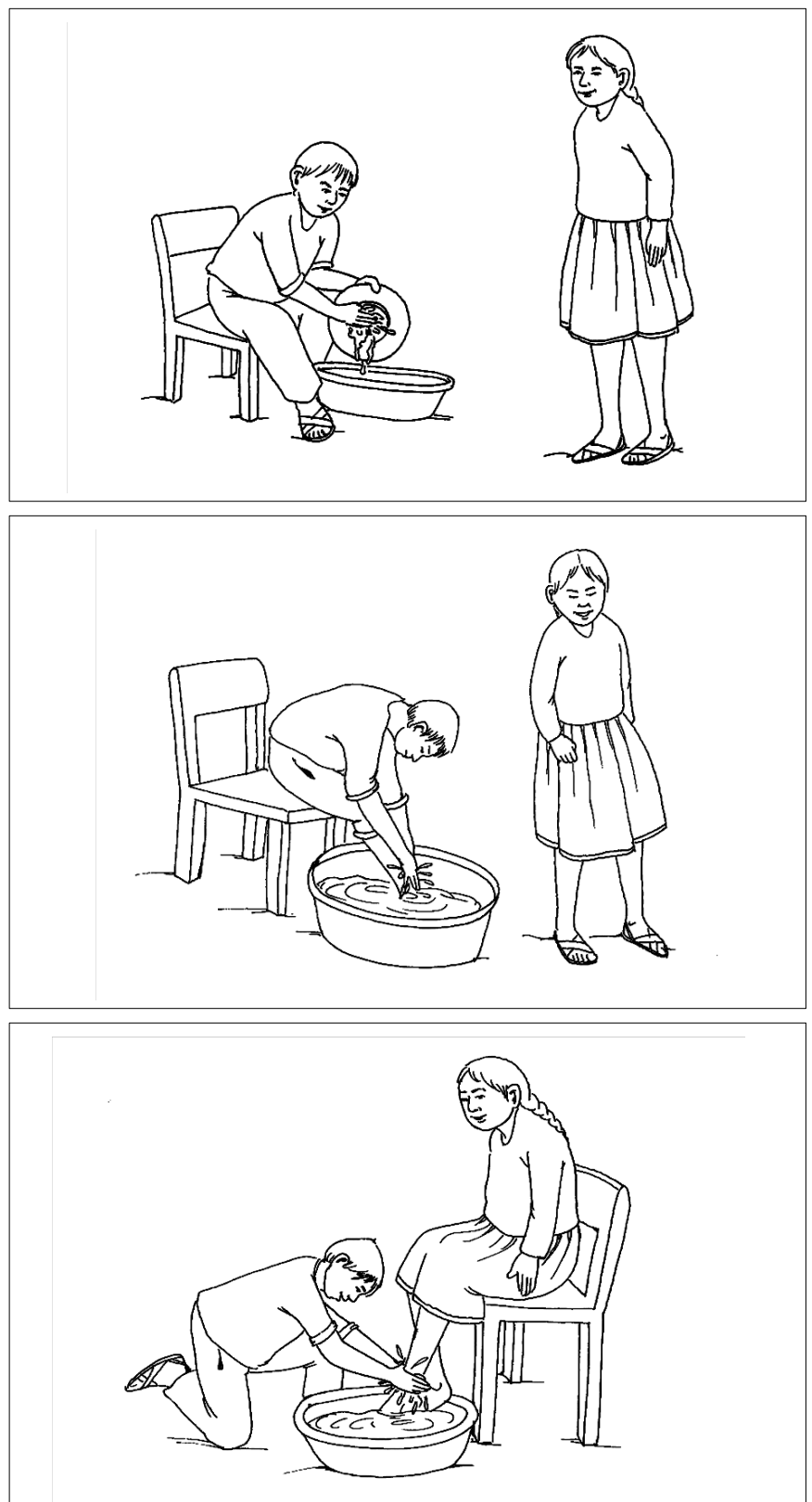

Figure 2: Sample from child picture description instrument 


\subsection{Appendix 2}
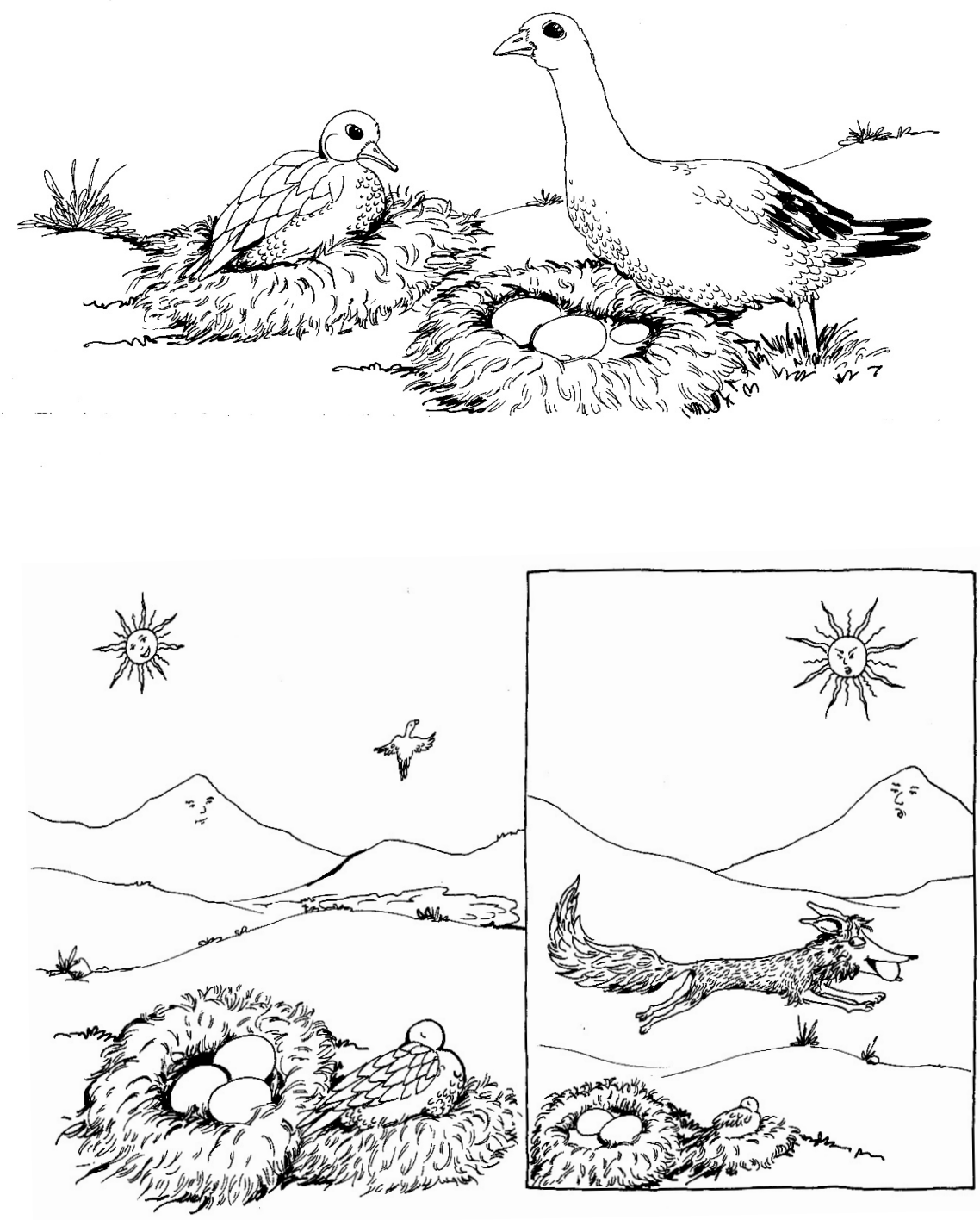

Figure 3: Sample from adult picture description instrument

\section{References}

Anglin, Jeremy M., George A. Miller, \& Pamela C. Wakefield. (1993). Vocabulary development: A morphological analysis. Monographs of the society for research in child development, i-186.

Aylett, Matthew \& Alice Turk. (2004). The smooth signal redundancy hypothesis: A functional explanation for relationships between redundancy, prosodic prominence, and duration in spontaneous speech. Language and Speech, 47(1), 31-56.

Bates, Douglas, Martin Mächler, Ben Bolker, \& Steve Walker. (2015). Fitting Linear Mixed-Effects Models Using lme4. Journal of Statistical Software, 67(1), 1-48.

Boersma, Paul \& David Weenink. (2016). Praat: doing phonetics by computer [Computer program]. Version 6.0.36, retrieved 9 November 2016 from http://www.praat.org/

Charles-Luce, Jan \& Paul A. Luce. (1990). Similarity neighbourhoods of words in young children's lexicons. Journal of 
Child Language, 17(01), 205-215.

Courtney, Ellen H. (2015). Child acquisition of Quechua evidentiality and deictic meaning. In M. Manley \& A. Muntendam, eds. Quechua Expressions of Stance and Deixis. Brill Studies in the Indigenous Languages of the Americas, Leiden. 101-144.

Courtney, Ellen H. \& Muriel Saville-Troike. (2002). Learning to construct verbs in Navajo and Quechua. Journal of Child Language, 29(03), 623-654.

Cychosz, Margaret. (2017). Functional load and frequency predict consonant emergence across five languages. UC Berkeley PhonLab Annual Report. University of California, Berkeley.

Denny, Margaret \& Richard. S. McGowan. (2012). Implications of peripheral muscular and anatomical development for the acquisition of lingual control for speech production: A review. Phoniatrica et Logopaedica, Folia 64(3), $105-115$.

Edwards, Jan, Mary E. Beckman, \& Benjamin Munson. (2004). The interaction between vocabulary size and phonotactic probability effects on children's production accuracy and fluency in nonword repetition. Journal of Speech, Language, and Hearing Research, 47(2), 421-436.

Edwards, Jan \& Mary E. Beckman. (2008). Some cross-linguistic evidence for modulation of implicational universals by language-specific frequency effects in phonological development. Language Learning and Development, 4(2), 122-156.

Edwards, Jan, Mary E. Beckman, \& Benjamin Munson. (2015). Frequency effects in phonological acquisition. Journal of Child Language, 42(02), 306-311.

Gallagher, Gillian. (2016). Vowel height allophony and dorsal place contrasts in Cochabamba Quechua. Phonetica 73:101-119.

Heggarty, Paul. (2006): Quechua - The language of the people who built this (Machu Pikchu) http://www.quechua .org.uk/

Hockett, Charles Francis. (1955). A manual of phonology (No. 11). Waverly Press.

Inkelas, Sharon \& Yvan Rose. (2007). Positional neutralization: A case study from child language. Language, 83(4), 707-736.

Jurafsky, Daniel, Alan Bell, Michelle Gregory, \& William D. Raymond. (2001). Probabilistic relations between words: Evidence from reduction in lexical production. Typological studies in language, 45, 229-254.

Kalt, Susan E. (2002). Second language acquisition of Spanish morphosyntax by Quechua-speaking children. Unpublished $\mathrm{PhD}$ dissertation, University of Southern California. https://suekalt.files.wordpress.com/2014/01/ tesis-kalt.pdf

Kalt, Susan E. (2009). The speech of children from Cusco and Chuquisaca. The Archive of the Indigenous Languages of Latin America: http://www.ailla.utexas.org. Media: video, text.

Kalt, Susan E. (2015). Pointing in space and time: deixis and directional movement in schoolchildren's Quechua. In M. Manley \& A. Muntendam, eds. Quechua Expressions of Stance and Deixis. Brill Studies in the Indigenous Languages of the Americas, Leiden, 25-74.

Kalt, Susan E. (to appear). The speech of adults from Cusco and Chuquisaca. The Archive of the Indigenous Languages of Latin America: http://www.ailla.utexas.org. Media: video, text.

Kuznetsova Alexandra, Per B. Brockhoff, \& Rune H. B. Christensen (2017). lmerTest Package: Tests in Linear Mixed Effects Models. Journal of Statistical Software, 82(13), 1-26.

Lee, Sungbok, Alexandros Potamianos, \& Shrikanth Narayanan. (1999). Acoustics of children's speech: Developmental changes of temporal and spectral parameters. Journal of the Acoustical Society of America, 105(3), $1455-1468$.

McAllister Byun, Tara. (2011). A gestural account of a child-specific neutralisation in strong position. Phonology, 28(03), 371-412.

Ménard, Lucie, Jean-Luc Schwartz, Louis-Jean Boë, \& Jérôme Aubin. (2007). Articulatory-acoustic relationships during vocal tract growth for French vowels: Analysis of real data and simulations with an articulatory model. Journal of Phonetics, 35(1), 1-19.

Oh, Yoon Mi, François Pellegrino, Christophe Coupé, \& Egidio Marsic. (2013). Cross-language comparison of functional load for vowels, consonants, and tones. In Proceedings of Interspeech 2013 (pp. 3032-3036).

New, B., Pallier, C., Ferrand, L., \& Matos, R. (2001). Une base de données lexicales du français contemporain sur internet: LEXIQUE. L'année psychologique, 101, 447-462. http://www.lexique.org

Pater, Joe \& Jessica A. Barlow. (2003). Constraint conflict in cluster reduction. Journal of Child Language, 30(03), 487-526.

Pye, Clifton, David Ingram, \& Helen List. 1987. A Comparison of Initial Consonant Acquisition in English and Quiché, in Keith Nelson and Anne van Kleeck (Eds.), Children's Language, Vol. 6, pp. 175-190. Hillsdale, NJ: Erlbaum. 
R Core Team (2015). R: A language and environment for statistical computing. R Foundation for Statistical Computing, Vienna, Austrat. http://www.R-project.org/.

Simons, G. F. (2009). Ethnologue: Languages of the World, SIL International. Retrieved May 1, 2009, from the website temoa : Open Educational Resources (OER) Portal at http://www.temoa.info/node/24358

Sloetjes, Han \& Peter Wittenburg. (2008). Annotation by category - ELAN and ISO DCR. In: Proceedings of the 6th International Conference on Language Resources and Evaluation (LREC 2008).

Stokes, Stephanie. F. \& Dinoj Surendran. (2005). Articulatory complexity, ambient frequency, and functional load as predictors of consonant development in children. Journal of Speech, Language, and Hearing Research, 48(3), 577-591.

Storkel, Holly. (2002). Restructuring of similarity neighbourhoods in the developing mental lexicon. Journal of Child Language, 29(2). 251-274.

Storkel, Holly L. \& Michele L. Morrisette. (2002). The Lexicon and Phonology: Interactions in Language Acquisition. Language, Speech, and Hearing Services in Schools, 33(1), 24-37.

Storkel, Holly L. \& Jill R. Hoover. (2011). The influence of part-word phonotactic probability/neighborhood density on word learning by preschool children varying in expressive vocabulary. Journal of Child Language, 38(3), 628643.

Surendran, Dinoj \& Partha Niyogi. (2006). Quantifying the functional load of phonemic oppositions, distinctive features, and suprasegmentals. Amsterdam studies in the theory and history of linguistic science series 4, $279,43$.

Torero, Alfredo. (1964). Los dialectos quechuas. Anales Cientificos de la Universidad Agraria 2: 446-478.

Watanabe, Akira. (2001). Formant estimation method using inverse-filter control. IEEE Transactions on Speech and Audio Processing, 9(4), 317-326.

Wedel, Andrew, Abby Kaplan, \& Scott Jackson. (2013). High functional load inhibits phonological contrast loss: A corpus study. Cognition, 128(2), 179-186.

Van Severen, Lieve, Joris Gillis, Inge Molemans, Renate van den Berg, Sven De Maeyer, \& Steven Gillis. (2013). The relation between order of acquisition, segmental frequency and function. Journal of Child Language, 40(4), 703740. 